\title{
Why Are some Older Persons Economically Vulnerable and Others Not? The Role of Socio-Demographic Factors and Economic Resources in the Nigerian Context
}

\author{
Olumide Adisa ${ }^{1}$ \\ Published online: 7 March 2019 \\ (C) The Author(s) 2019
}

\begin{abstract}
Socio-demographic factors and economic resources can help to explain why some older people may be more economically vulnerable than others in developing countries. Drawing on data from a representative sample of urban households from the 2010 Nigerian General Household Panel Survey (NGHPS), this study examines economically vulnerable older persons in Nigeria using a log-linear regression model to identify determinants of economic vulnerability. Sociodemographic factors such as age, household size, household structure, and regional location accounted for significant economic capacity differences among older groups in urban settings. This article discusses some policy options for improving the welfare of economically vulnerable older people in Nigeria.
\end{abstract}

Keywords Older people · Economic vulnerability · Nigeria $\cdot$ Sub-Saharan Africa · Economic welfare

\section{Background}

A significant proportion of older people in developing countries are largely economically disadvantaged yet many older people are often excluded from social protection programmes. In Europe, retired older people have greater access to well-functioning social pension schemes as a reliable source of income, although the sustainability of pensions systems in ageing European countries remain questionable (Walker and Foster 2014). Whereas their counterparts in Sub-Saharan

Olumide Adisa

o.adisa@uos.ac.uk

1 Suffolk Institute for Social and Economic Research, University of Suffolk, Ipswich, Suffolk, UK 
Africa (SSA) - with the exception of Southern African countries (Niño-Zarazúa et al. 2012; Devereux and White 2010) ${ }^{1}$ — lack sufficient social security arrangements to mitigate economic vulnerability during old age.

Nonetheless, the key drivers of economic vulnerability and resulting consequences are likely to be complex and varied. Contrary evidence in developed and developing countries suggests that social pensions on its own are not sufficient. For instance, in OECD (Organisation of Economic Co-operation and Development) countries, even though older people are covered by effective social protection systems, older people have higher poverty rates than their younger counterparts (UN 2013b; Walker and Foster 2014). This complexity is further heightened by the inherent difficulties in untangling economic vulnerability among older groups in SSA states with high levels of poverty (Kakwani and Subbarao 2005; UN 2013b). It is a well-known fact that high poverty rates are characteristic of many SSA states including Nigeria. Much of SSA is poor, with about 1.2 billion people living on less than $\$ 1.25$ a day in developing countries; and $47.5 \%$ of this estimated figure residing in Sub-Saharan Africa. ${ }^{2}$ Globally, poverty rates tends to be higher among older people than other age groups (UN 2013b; UNFPA and HAI 2012), however, a recent study by Castañeda et al. (2018) reveals contrary evidence that the demographic profile of poverty is mostly young and rural in some countries. It is worth noting that the study excluded 22 Sub-Saharan countries, which accounts for a total 185 million people.

Context-specific evidence in high poverty settings like Nigeria's reveal that in the absence of social protection schemes, many older people remain in work throughout their life span. According to the United Nations (UN), it is estimated that $40 \%$ of older people in SSA are economically active. This old-age labour participation rate in SSA is relatively high, compared to the estimate of 7\% in Europe (UN 2013b, p.50). As the UN's 2013 report further notes, many older people in SSA have no choice but to work, if they are to overcome economic vulnerability in later life.

The importance of understanding the key drivers of economic vulnerability in old age cannot be disputed. Its emergence as a pressing developmental issue in SSA is indicative of a recognition that older people are an under-researched group and that there is much that we do not know about the needs and characteristics of older people in developing countries. Regrettably, dominant international development concerns for older people in much of SSA tend to view older people as one homogenous group and assume that inequalities among older populations do not matter (Aboderin 2010). These two assumptions have greatly influenced how older people have been predominantly studied by research commissioned by dominant international institutions, especially the UN.

In Nigeria, the government has on one occasion identified that there are certain important socio-economic and demographic characteristics which differentiate older people from each other (NPC 2003). In the government's only report on

\footnotetext{
${ }^{1}$ These recent studies have shown that existing non-contributory pensions in Southern Africa have helped to reduce old-age poverty Niño-Zarazúa et al. 2012. Social Protection in Sub-Saharan Africa: Getting the Politics Right. World Development, 40, 163-176, Devereux and White 2010. Social protection in Africa: Evidence, politics and rights. Poverty \& Public Policy, 2, 53-77, Barrientos 2007. Introducing basic social protection in low-income countries: Lessons from existing programmes. Brooks World Poverty Institute Working Paper..

${ }^{2}$ PovCalNet (World Bank); accessed May 2015.
} 
older people Nigerians entitled, 'The Older people', published by the National Population Commission in 2003, older people were described as a diverse group.

Besides the diversity of vulnerable older groups accounting for different ageing experiences, social, political, and economic factors play a key role in understanding why the economic situation of older people has not been prioritised in Nigeria. In 2003, Nigeria officially identified older people as a specific vulnerable group with the publication of a landmark report, 'The Older people, by the National Population Commission. This 2003 report presented the draft National Policy on Ageing (NPC 2003). Since then, the policy has remained in draft form. There are two possible reasons for this lack of political will: 1) the population ageing argument often invoked in the demography of ageing literature has been less successful in seizing the attention of policymakers in the in Nigeria and has undermined the strengths of the demography of ageing arguments in prompting policy action in Nigeria.; and 2) relative to some countries, there is no doubt that the amount of older Nigerians is significant in absolute terms. The percentage of older people in Nigeria in 1991 versus 2010 are equally remarkable in that there has not been a dramatic demographic change, which could perhaps explain one the reasons why older people's needs are not seen as a priority - at least in relation to the rest of the country's population (see Table 1).

In 2006, two US Census Bureau statisticians surmised that the older people population (those 50 years of age and above) in Nigeria will almost double, from 13.7 million in 2006, to 25.4 million by 2030 (Velkoff and Kowal 2007). However, in comparison to other groups in Nigeria, the older people population is relatively small, at $4 \%$ of the total country's population of 174 million (UN 2013a).

There is no doubt that older people in Nigeria are growing demographically, but it is likely that not all older people are poor or dependent. In the next sections, we explore why some older people are more economically vulnerable than other groups.

\section{Methodology}

The Nigerian General Household Panel Survey (NGHPS) collected data on households in two rounds in 2010. The NGHPS is a nationally representative survey of households with detailed information on consumption expenditure. Consumption Expenditure Surveys like the NGHPS are more superior to the National Demographic Health Surveys due to its representativeness of different types of consumption expenditure data. Nigeria's National Demographic Health Surveys in 2008 (NPC) captures health

Table 1 Older population and sex ratio in Nigeria, 1991 and 2010

\begin{tabular}{lll}
\hline & 1991 & 2010 \\
\hline $\begin{array}{ll}\text { Percentage of older people to whole population } 60+ \\
\text { Sex ratio (for every 100 older female) }\end{array}$ & 1 in $20(5 \%)$ & 1 in $14(7.1 \%)$ \\
\hline
\end{tabular}

For comparison purposes with the Census data, the age starting point has been restricted to 60 years old and above

Source: NGHPS 2010 (http://microdata.worldbank.org/index.php/catalog/1002) \& NPC 2003 
information and spending for the adult working population only - 15-49 years old for women, and 15-59 years for men, limiting its usefulness for a study of older people households, while, the NGHPS 2010 (http://microdata.worldbank.org/index. $\mathrm{php} / \mathrm{catalog} / 1002$ ) data used in this study captures information on all age groups. It contains household information on total consumption expenditure, food and non-food expenditure, household size, region, employment. Consumption expenditure was collected over a one-year period on a household basis, and this was sourced from the first round of the panel survey. The difference between the first and second round was not significant, so the issue of selection bias should not arise. Education and Occupation were collected on an individual basis. The NGHPS comprises of 5000 households from which I draw this study's urban sample of 1620 urban households: 799 households are elderly households, made up of 1063 individuals aged 50 years and above. Tables 2 and 3 shows that description of the sub-sample used in this study. The analysis in subsequent sections comprises of households with at least one older person in Urban Nigeria.

In the related literature, there is a growing literature on studies that empirically focus on identifying economically vulnerable older people in developing countries using secondary data analysis, for example, Lloyd-Sherlock 2006; Alam 2006 and the various WHO SAGE papers (2005-date). Later, I discuss the rationale for the selection of some of this study's variables. I then formulated some expectations about the relationships between the socio-economic variables and this study's economic measure (consumption expenditure).

\section{Model Specification}

Intuitively, I can interpret the model that any increasing or decreasing effects on household consumption or income are likely to be key determinants of economic vulnerability. The determinants are on the right side of Eq. 1 below, and they feature as the explanatory variables in the estimation.

Mathematically, this study's simple OLS model can be expressed as follows:

$$
\mathrm{Y}_{\mathrm{i}}=\beta_{0}+\beta_{1} \mathrm{X}_{1}+\ldots+\beta_{\mathrm{k}} \mathrm{X}_{\mathrm{k}}+\mathrm{e}_{\mathrm{i}}
$$

Where $\mathrm{Y}$ is consumption per capita; and this study's dependent variable, $\alpha$, is a constant; $\beta_{1 \text { to }} \beta_{\mathrm{k}}$ are unknown coefficients; and $\mathrm{e}_{\mathrm{i}}$ is an error term.

Table 2 Household size and composition of households with older people in Urban Nigeria, 2010

\begin{tabular}{lllll}
\hline & \multicolumn{3}{l}{ Urban households with one or more older person 2010 } \\
\cline { 2 - 5 } Measures & Mean & SD & Min & Max \\
\hline Household Size & 5.13 & 3.09 & 1.0 & 22 \\
Number of older person- 50+ & 1.34 & 0.54 & 1.0 & 4 \\
Number of working age adults (15-49 years) & 2.27 & 1.99 & 0.0 & 16 \\
Number of children (0 to 14 years) & 1.51 & 1.86 & 0.0 & 15 \\
\hline
\end{tabular}

Source: NGHPS 2010 (http://microdata.worldbank.org/index.php/catalog/1002); $N=799$ 
Table 3 Average age of older people, and by gender; Urban Nigeria, 2010

\begin{tabular}{llll}
\hline Age and Survey Year & Mean (SD) & Max & N \\
\hline Age in 2010 & $61.48(10.12)$ & 102 & 1063 \\
Age in 2010 (Female) & $61.48(10.13)$ & 95 & 502 \\
Age in 2010 (Male) & $61.48(10.12)$ & 102 & 561 \\
\hline
\end{tabular}

The sample comprises of older people aged 50 years and above

Source: NGHPS 2010 (http://microdata.worldbank.org/index.php/catalog/1002). Standard deviation in parentheses. $N=1063$

This study's regression specification for the consumption model can be expressed as follows:

$$
\begin{aligned}
\mathrm{LnY}= & \beta_{0}+\beta_{1} \text { gender }+\beta_{2} \text { HHsize }+\beta_{3} \text { married }+\gamma \text { age categories } \\
& +\beta_{4} \text { education }+\gamma \text { region dummies }+\gamma \text { occupation dummies } \\
& +\gamma \text { home ownership dummies }+\varepsilon_{\mathrm{i}}
\end{aligned}
$$

In this section, I present the quantitative evidence from the estimated model. The analysis primarily examines the socio-economic factors that influence economic vulnerability. The dependent variable was the log of consumption per capita, the proxy for economic vulnerability. The other covariates are the hypothesised determinants, which I earlier discussed above, in Eq. (2). I accepted a log-linear functional model as the best fit, and I am satisfied that the model does not suffer from harmful omitted variable bias and multicollinearity based on this study's diagnostic test results discussed in the next section.

\section{Robustness Analysis}

A test of multicollinearity is performed. VIF (variance Inflation factors) values are estimated after the regressions using Stata's 'estat vif' command. The rule of thumb is that this ought not to be greater than 10 (O'brien 2007).

Results in Table 4 shows a very low VIF value of 3.32, leading me to believe that if collinearity is present, it is not harmful. I am satisfied that the model does not have an omitted variable bias based on the Ramsey Test. I utilised age categories instead of age, and I included $\mathrm{AGE}^{2}$ and $\mathrm{HHSIZE}^{2}$ to capture non-linear effects. $\mathrm{AGE}^{2}$ did not improve the model much, but $\mathrm{HHSIZE}^{2}$ did. Therefore, I excluded the former and included the latter. Marital status was excluded for the same reason as $\mathrm{AGE}^{2}$.

Additionally, an omitted variable bias occurs when a model has been mis-specified because it has excluded a key explanatory variable model that is closely related to the dependent variable in the model. The convention is to use a diagnostic test such as the Ramsey RESET specification tests. The estimates would indicate whether there is an omitted bias error.

The debate on resolving an omitted variable bias is controversial. Notable econometric textbook authors advocate for the inclusion or exclusion of the omitted variable 
Table 4 Robustness Tests Results

DV = Log consumption per capita)

Test statistics (k)

OLS regression

Multi-collinearity:

Variance Inflation Factor (VIF) test

Specification test (Ramsey's RESET test) $\quad 1.04$ ( $p$ value $=0.3820)$

$* \mathrm{p}<0.05$ indicates significance at the $5 \%$ level; ** $\mathrm{p}<0.01$ at the $1 \%$ level; at $* * * \mathrm{p}<0.001$ at the $0.1 \%$

Source: NGHPS 2010 (http://microdata.worldbank.org/index.php/catalog/1002)

to solve this problem. Applied econometric researchers argue that in practice, it is problematic to do so and may result in inefficiency of the model if variables are included or excluded without any basis, to eliminate the specification issue. Ken Clarke's well-cited papers present the various debates on the issue (see Clarke (2005). Nevertheless, there is a consensus that theory and empirical evidence should be the main guiding strategy in the inclusion of any variable in the model, and I support this view. The changes of $\mathrm{R}^{2}$ and changes in the coefficients of other explanatory variables are two criteria for identifying the usefulness of including an additional variable.

The convention in the empirical literature is to relax the assumptions of linearity in this study's model by considering that one of the variables in the model may have a non-linear relationship with another variable, which has been excluded. It is a commonly held practice to control for unexplained effects in household size because it may have a non-linear relationship with expenditure per capita, and the convention is to include a multiplicative household size variable $\left(\mathrm{HHSIZE}^{2}\right)$ to capture all non-linear effects.

\section{The Selection of Variables for this Study}

This paper argues that the diversity of older groups can help to explain why some urban older people Nigerians are likely to be more economically vulnerable than others. I draw on the economics and sociology literature for some indications on the likely socio-demographic factors that can depict these differences. In Sociology, the main socio-economic characteristics are often viewed to as 'occupation, education, and income' (De Vos 2005, p.88). Other examples of sociodemographic factors include: age, and gender. These socio-demographic factors may manifest themselves at the individual and household level. Besides income, some socio-economic characteristics are likely to be important in explaining economic vulnerability differences among older people.

Age is an important variable in understanding the welfare differences among older people. Grundy's (2006) study on older Europeans, which identified vulnerable older people based on those that are very old. Theoretically, household welfare increases with age due to asset accumulation and experience of the individual. Income begins to decline due to withdrawal from the labour force and declining productivity at older ages 
(Modigliani and Brumberg 1954; Deaton 1992; Börsch-Supan 1992; Alessie and De Ree 2009). It has become quite common practice in the empirical literature to control for age in a household welfare model and as an important determinant of older people household welfare in developing countries (Deaton and Paxson 1995; Deaton and Paxson 1998b; Duflo 2003; Maitra and Ray 2003; Van de Walle 2013; Woolard and Klasen 2005). However, it is worth noting that many older people, regardless of gender, continue to work beyond the recommended retirement age of 60 years of age or after thirty-five years of service in Nigeria (see Table 5). ${ }^{3}$

Age effects are important in understanding the economic situations of older people. On a societal level, It can determine how much support is given to older people (Harris 2007) and how much access some may have to income generating opportunities (Maharaj 2012). Barrientos et al. (2003), in their review of old-age poverty studies in developing countries, found evidence of a decline in economic opportunity with age. The authors use household surveys pulled from different sources to show that that poverty increases with age. Using a survey of over 500 people aged 60 years and over in Thailand, Lloyd-Sherlock (2006) found age differences in economic vulnerability among the older people.

With respect to gender, feminist theories of ageing prioritise gender as a factor that can affect the experience of ageing (Calasanti, 2010b, a). These theorists take the position that gender relations can identify differential ageing experiences between men and women; and women's differential access to material resources (Giddens 2009; Johnson et al. 2005). Other examples can be found in sociological studies where household decision-making status is inferred from gender-based assignments of domestic labour (Giddens 2009; Oppong 2006).

Gender is now widely recognised as a variable that can influence economic welfare outcomes, and as such, it has become common practice to control for gender in applied work. The role of female household headship has been well-debated over the years.

In one study by Okojie (2002), the author also found that female-headed households are more likely to be poor compared to male-headed households in all four survey periods. Mberu (2007), drawing on data from a Demographic Health Survey in Nigeria, found a similar result. The gender variable is a dummy that could highlight any gender disparities that may exist between female-headed older people households compared their male older people counterparts. Anyanwu (2011) also found a similar result. Conversely, some researchers have found contrary evidence in other SSA countriesmany of these studies are somewhat dated. These authors surmise that FHHs are not in the majority among poor households in Africa. Appleton (1996), using the 1992 Integrated Household Survey in Uganda, found contrary evidence. The author did not find any significant gender differences in consumption or income levels in Uganda, although, in urban areas, it was found that female-headed households and households headed by widows had lower economic welfare.

In Malawi, one study by Mukherjee and Benson (2003) on the determinants of poverty found inconclusive gender differences. The study draws data from the 1997/98

\footnotetext{
${ }^{3}$ The concept of compulsory retirement does exist in Nigeria based on the provisions of the Nigerian Civil Service Act (Laws of Federation of Nigeria) at thirty-five years of service or 60 years of age, particularly for those that work in the formal sector. However, due to poverty and other reason, older people may choose to continue to work in advanced ages in the private sector.
} 
Table 5 Mean days worked post-retirement age at both 60 years and 65 years by gender, Urban Nigeria, 2010

\begin{tabular}{|c|c|c|c|c|}
\hline Days worked per year & All & Female & Male & Difference \\
\hline \multicolumn{5}{|c|}{ Assuming retirement age $=60$ years } \\
\hline Mean & 261.74 & 270.43 & 254.70 & \multirow[t]{4}{*}{ NS } \\
\hline S.D & 108.55 & 105.02 & 111.19 & \\
\hline Min & 0.0 & 0.0 & 0.0 & \\
\hline Max & 364 & 364 & 364 & \\
\hline \multicolumn{5}{|c|}{ Assuming retirement age $=65$ years } \\
\hline Mean & 267.97 & 271.05 & 265.19 & \multirow[t]{4}{*}{ NS } \\
\hline S.D & 105.86 & 106.71 & 105.57 & \\
\hline Min & 0.0 & 0.0 & 21.0 & \\
\hline Max & 364 & 364 & 364 & \\
\hline
\end{tabular}

NS denotes not significant at the 5 or $10 \%$ level

Source: NGHPS 2010 (http://microdata.worldbank.org/index.php/catalog/1002)

Malawi Integrated Household Survey. They also use model simulations to analyses effects of poverty changes on certain household characteristics such as education and labour employment. Therefore, it has become good practice to control for gender in any household welfare model.

Educational Achievement There is a clear consensus about the importance of education in any economic welfare study on individuals or households. The human capital theory surmises that education is a key determinant of household income (Becker 1964). According to Becker, there is a positive relationship between educational acquisition and wage earnings. Using Consumption Expenditure Surveys in Nigeria over four periods (1980, 1985, 1992, and 1996), Okojie (2002) found that education reduced the likelihood of household poverty in Nigeria. Elsewhere in Africa, Mukherjee and Benson (2003), using data from the 1997-98 Malawi Integrated Household Survey found that educational attainment would be poverty-reducing in Malawi.

Similarly, education has been found to improve household economic welfare in Cote D'Ivoire (Grootaert 1997). Citing an earlier study, Appleton (2000) presented evidence to show that there are positive returns on household welfare in Sub-Saharan African countries from receiving secondary education schooling.

Himaz and Aturupane (2011) examined the impact of education on household economic welfare in Sri Lanka using household surveys from 1985 to 2006. The authors applied quantile regression techniques and found that there is an incremental value in household welfare with an extra year of education, suggesting that educational acquisition is important in the labour market.

Occupation As an older person, what one is doing or did in the labour market is also important. Some occupations have been found to command higher earnings than others based on the level of skills demanded by labour market forces. For instance, in much of Africa, farm income has been found to be lower than non- 
farm income (Fox 2015; Zimmer and Das 2013). In Nigeria, Appleton et al. (2008) found significant income differences between those in agricultural occupations and those in professional occupations.

According to Alem and Söderbom (2012) labour market status affects consumption levels. In their study of urban Ugandans by using household surveys in 2004, 2004, and 2008 and OLS regression analysis, they found that those in the labour force had higher consumption growth rates compared to those out of the labour force. In addition, public sector workers and casual workers where most affected by food price shocks. This evidence suggests that what one does in the labour market is likely to be important in understanding old-age economic vulnerability.

The evidence on education and occupation on economic welfare in African contexts is conclusive, and so it would be problematic to exclude these variables as potential correlates. In addition, some of the studies in this review have noted that, economically inactive individuals may have alternative sources of income, which may be important. I do not present the results in this study, but I found that there were issues with the completeness of the rental income data in the NGHPS (Adisa 2016), in line with other empirical studies on developing countries (Deaton 1997; O'Donnell et al. 2005). Nonetheless, owning a home in old age could be considered welfare enhancing so I controlled for this in the regression model. .

Marital status is one that has not been considered to be very important, due to the study's assumption of a unitary model. However, in order to ensure a correctly specified model, marital status is a variable that needs to be controlled for. The underlying theory of marriage was developed by Becker (Becker 1973, 1974) and has formed the theoretical framework of many empirical studies on the family development. According to Becker, women will choose to marry if there are welfare benefits compared to being unmarried, and the possibility of being married decreases if there are no perceived welfare benefits to marriage. Becker's model has greatly influenced labour supply decision-making and bargaining power studies (Doss 2013). Additionally, Becker's theory of marriage posits that people who are married are better off than those who are single due to the specialisation advantages that marriage brings (Becker 1973, pp. 813-814).

Using data from the 2001 Census and the South African Labour Force, Lam et al. (2006) found that marital status had differential effects on labour force participation among South African older people 50-75 years old. They found that unmarried older people women were more likely to work, with the largest effect being from divorced older people women. Married older people men, on the other hand were found to have the highest probabilities of employment compared to divorced, widowed, or never married men-married older people men had probabilities of at least 10 percentage points higher. This evidence suggests that being married may carry some advantages. Similarly, using data on 17,009 women aged 50 and over from the WHO's Survey of Ageing and Adult Health for China, Ghana, India, the Russian Federation and South Africa, LloydSherlock et al. (2015) found associations between widowhood and socioeconomic status in all five countries.

Therefore, marital status is a useful variable to include in the model. In the NGHPS, marital status consists of five categories: married, separated, divorced, widowed, and never married. 


\section{OLS and Quantile Regression Results}

Appendix Tables 6 and 7 presents OLS and quantile regression results from this study's estimations of the economic vulnerability (EV) model. Column (1) presents the OLS regression estimates, and Column (2)-(5) presents the quantile (median) regressions estimated at various points: $25 \%, 50 \%, 75 \%$, and $90 \%$. Both the coefficients of OLS and quantile regressions are interpreted in the same way; however, the coefficients of each quantile regression in Column (2)-(5) should be interpreted as the impact of a household having a higher or lower consumption quantile conditional on the whole economic vulnerability distribution in each corresponding quantile. In all the regressions, I estimated the equation using the same controls in Equation (6). Some interesting findings emerged from the empirical analysis.

In line with this study's expectations, the age of the older people household head has a statistically significant impact on consumption allocation in the model - it is negatively related to our welfare measure of economic vulnerability in all cases. Intuitively, as the age of the household head becomes more advanced, the household is likely to suffer more from economic vulnerability compared to their younger-old counterparts. This confirms that theoretical expectations between age and income in the empirical literature, (Deaton 1992; Börsch-Supan 1992; Alessie and De Ree 2009). Those at the more advanced ages of 90 years and above reduced consumption allocations by $98 \%$, although this association was statistically significant at $10 \%$.

In Column (1), the age relationship was significant at the 5\% significance levels for advanced ages. The age differentials differed by quantiles. Comparing column (3) and (5), I see greater age differentials in levels of economic vulnerability at the median of the distribution compared to those at the higher end of the distributions. These age differentials also vary within quantiles, especially at the top-end of the probability distribution. At a cut-off point of $75 \%$, age is negatively associated with consumption allocations at the $5 \%$ and $1 \%$ statistical significance.

In line with this study's expectations, household size and household structure types were mostly statistically significant in the consumption allocation model. They are negatively related to consumption levels and are statistically significant in all cases.

These are indications that as the household size becomes bigger, there may be positive effects on consumption allocation. Controlling for non-linear effects in household size, the squared household variable is positively related to consumption levels, suggesting that there might be scale economies advantages as the household becomes significantly larger. This supports the scale economics argument and some studies in Nigeria. In addition, single-headed older people households in the lower quintile of household are better off than other single-headed households in the middle and higher quintiles. When household size is doubled, it increased consumption allocation by $0.7 \%$ in the OLS and $0.9 \%$ in the middle quantile, and $1 \%$ at the $90 \%$ cut-off point.

Region is also an important determinant. The Northern region is the poorest region in Nigeria. In the OLS and the lower to the higher quintile (Column 1-4), I found mixed evidence. While in the highest quintile, I found a consistent 
negative relationship with consumption level. For the South South and South West, often described as the richest zones in Nigeria, the differences were largely insignificant in all cases. Across all the models, region was weakly related to economic vulnerability. Across the quantiles, the differences are more glaring for the Northeast and Southeast regions, which were significant at the 5\% significance level. In the highest quintiles, living in the South South region did not decrease consumption per capita significantly. One explanation for this mixed result is partly due to the high aggregate levels of poverty in Nigeria across all zones, which often makes it difficult to find glaringly obvious regional differences in economic welfare outcomes. Nevertheless, from available statistics in Nigeria, the differences in regions suggest that there are likely to be differences in consumption allocation levels for households, confirming regional location as a tested determinant.

In the model, occupation and education were good controls, although they were largely insignificant in the model. Only in one case in the OLS model was working in religious occupations (compared to self-employment) significant. It would difficult to infer a strong relationship between occupation and consumption allocation based on this single occurrence. In a separate study, I demonstrated that both variables were likely to be important to the economic welfare of older Nigerians, on an individual level using descriptive analysis. On a household level, it is possible that any advantages that education and occupation bring, on an individual level, does not directly influence the consumption allocation welfare measure in the way that theory would suggest. In relation to these two variables, understanding the decision-making at the household level may better reveal their true welfare-improving nature through consumption allocations.

Other controls such as gender were not significant. Gender is often thought to be an important to determining levels of economic resources available to a household, based on the literature (Appleton 1996; Okojie 2002). However, the lack of a significant relationship in this study's model is likely to be because of other unobservable factors, which from the data are difficult to identify such as cultural and institutional factors, as Quisumbing et al. (2001) found for Ghana and Bangladesh. Additionally, intra-household bargaining processes may also be influencing allocation of resources within households. One study by, LloydSherlock (2006) found no apparent gender differences in economic vulnerability among Thai older people, suggesting that if gender is likely to be important in understanding why some older people or households are more economically vulnerable than others, its relationship to economic welfare measures is likely to be a complex relationship requiring a more comprehensive approach to uncover the cultural and bargaining processes in Nigerian households. In their recent paper, Lloyd-Sherlock et al. (2018) have attempted to capture these bargaining processes for dependent older people in Mexico and Peru using in-depth family case studies linked to a wider set of quantitative survey data.

Research has shown that the economic burden on poor urban older people households in Nigeria without employer-provided housing or an owned home is likely to be higher than that of other households (Ndubueze 2009; Aribigbola 
2008). For urban older people households, it is not evident that there is an association between housing tenure types and the consumption allocation welfare measure based on the data in the NGHPS 2010 (http://microdata.worldbank. org/index.php/catalog/1002). Without information on housing prices and how much was paid at the purchase date, it is difficult to ascertain if those that own homes bought them using loans of some kind, since the repayment may place a huge demand on older people households.

In light of this, this study's results should not be taken as the sole basis for targeting policies towards older people households. Nevertheless, the NGHPS has provided useful correlates of economic vulnerability. It is the first study to utilise both OLS and Quantile regressions to examine the association between socio-economic factors on economic vulnerability amongst urban older people households. I found that this study's key determinants of economic vulnerability are: age of household head, household size, household structure, and regional location. These findings have significant policy implications as shall be seen in later text.

The strong confirmatory evidence found between age and consumption allocation is consistent with the findings in the literature. This study's findings on age are similar to studies on households in Nigeria where poverty increases with age (Mberu 2007; Appleton et al. 2008; Anyanwu 2011). Intuitively, these findings highlight that economic capacities of older people are likely to worsen as they grow older. As expected, I found some support that there are regional disparities in economic vulnerability amongst older people households. Untangling the regional disparities would probably require a state-level and community analysis to verify the consistency of the disparities, which I do not have in this dataset.

Other similar household composition measures such as proportion of children and number of working age adults may not capture all the household composition effects on economic vulnerability. In addition to household size, issues relating to power, nutritional needs, and labour allocation decisions at the household level would provide more information. There were educational and occupation differences between those in the in the self-employment sector compared to those working in the private and public sectors. On a household level, these patterns were not observed suggesting that the association of these two variables with consumption allocation is likely to be more difficult to untangle at the household level.

Despite the mixed findings in this paper, the analysis is a useful addition to the household welfare studies as it adds an older people household dimension to the empirical literature. This study's Box-Cox transformational analysis found the loglinear function most preferable. Results from this study's robustness tests revealed that this study's reduced form model was adequately specified, and multicollinearity was weak or absent. This work has the advantage that it can be routinely replicated as the NGHPS lengthens over the next few years. Secondly, this study has presented a robust functional relationship between socioeconomic determinants and consumption allocation.

The model could potentially also be applied to other settings to study older people households. Although, the model is limited for the purposes of conducting a dynamic analysis of economic vulnerability, the model could be 
extended to include other useful variables if the data permits, such as examining the effects of the identified determinants on other welfare outcomes such as housing affordability outcomes.

Finally, in this empirical analysis, I have identified the determinants of economic vulnerability through a consumption allocation model. I have also shown that some older people households are more economically vulnerable than others due to the age of the household head, they structure and size of their household, and the region they reside in.

Nonetheless, the limitation of using a one-period household data, the most wellknown is that one cannot make claims to causality. All this study's results highlighted the correlational relationships between the socio-economic factors and consumption allocation, the main welfare measure of economic vulnerability, at a specific point in time. According to Deaton and Paxson (1998a, b), one would require panel data to assess economic vulnerability over time. Therefore, this study can be viewed as providing a static view in examining the determinants of economic vulnerability through consumption allocation. In the next section, I discuss some policy recommendations.

\section{Policy Implications for Reducing Economic Vulnerability among Older Nigerians}

While in some SSA countries, social policies are aimed at ensuring a minimum level of social wellbeing for its older people citizens through its insurance schemes, old-age pensions, and social benefits; in Nigeria, the reverse is the case, and many of the social policies in Nigeria are tied to formal sector employment. Given Nigeria's track record of policy failures, it is important that the basis for implementing the ageing policy be based on a strong knowledge base and longterm planning, and that the assumptions and ambiguities are critically examined to confirm its accuracy.

This study accepts that Nigeria is faced with scarce resources, and in times of economic constraints, poor or limited social welfare programming tends to be the norm (Estes et al. 1979). Nonetheless, there is scope for the government to take a more active role in prioritising the needs of its older people. The existence of a draft National Policy on Ageing is indicative of its commitment to older people Nigerians, but without a shift in the government's conservative ideology of social welfare policymaking, it is unlikely that the policy will be implemented successfully.

Policy recommendations must go together with an understanding of the economic and political contexts as well as the economic welfare needs of the older people. On a micro-level, understanding the key drivers of economic vulnerability is a good starting point in generating evidence on those older people that are likely to be economically vulnerable and who may require urgent intervention.

There is no doubt that the lofty goals articulated in the National Policy on Ageing, would help reduce economic vulnerability amongst older people if successfully implemented within an enabling environment. The National Policy on 
Ageing is a robust policy because it covers multi-dimensional aspects of welfare. In the policy, the Nigerian government includes income security, health, and housing, which it describes as essential to the wellbeing of older people. It is reasonable to advocate that the government should stand by its stated commitments by ensuring that adequate funding is available upon implementation by planning beyond the short-term but effective monitoring mechanisms should be instituted to ensure that the minimum $3 \%$ percent of budget allocations, which it is to be earmarked specifically for the support of older people, is actually spent to meet the needs of older people.

The success of the National Policy on Ageing depends on addressing the ambiguities and obstacles as well as setting its policy priorities in line with evidence on needs. With respect to the latter, this study has shown that some older people are more economically vulnerable than others, and these welfare differences can be explained by certain socio-economic and demographic factors. In the first instance, the focus should be on urban older people Nigerians from the age of 50 and above; those living in the Northeast, Northwest, and Southeast areas of the country; those living in larger and more complex households; and those that are economically inactive. This study recommends that with proper planning, specific welfare programmes should be developed and managed at the national level for these groups.

\section{Pension Reform and Cash Transfers}

In the NGHPS, older people reported pension income, although the data suggests that coverage is still very limited. Less than $1 \%$ report receiving pensions as a source of income, suggesting that there is scope to incorporate other social protection schemes that do not depend solely on past formal employment. Pensions are the most common method for reducing old-age economic insecurity (Casey 2011; Phillipson and Dannefer 2010). There are essentially two types of pensions: contributory and non-contributory pensions; the former refers to the contributions made during active work life which is drawn down during retirement years; non-contributory pensions are typically in the form of universal cash transfers which are automatically paid to a person by reason of age or disability regardless of one's background (Barrientos 2004). This study has highlighted a gap in knowledge on what works best for economically vulnerable older people in Nigeria.

Following the Pension Reform Act 2004, Nigeria established a national contributory pensions system for all private and public-sector workers. The key obstacle impeding the effectiveness of the current national security programme to deliver economic security for older people lies is that this is an under-researched area, which means that there is a lack of evidence to enable an understanding on the neediest of older people. It is likely to take several years for the current pension reforms in Nigeria to have any visible impact in providing a decent source of income to present ageing cohorts. Therefore, the government needs to adopt policies that help support household budgets.

Non-contributory pensions have the advantage of not discriminating based on labour force participation. The most common form of non-contributory pensions is cash transfers to the older people. Given the strong evidence in favour of cash transfers in reducing poverty and vulnerability among older people groups in Latin America and Southern countries of Sub-Saharan Africa (Barrientos and Villa 2015; Barrientos 2004, 
2007; Case 2004), the government should incorporate this aspect to meet the welfare needs of older people Nigerians who have no source of income of their own and come from very poor households. For this economically vulnerable group, an older people monthly allowance could be devised which offers a complementary means of achieving the economic society objective articulated in the ageing policy in Nigeria. Under this proposed scheme, a fixed payment (annually adjusted for inflation) could be made automatically upon an individual attaining age of 50 years old; this monthly amount can be determined empirically, and it can be investigated in future research work.

The argument against the universal pension scheme is that it would be too expensive for low-income countries (Kakwani and Subbarao 2005). However, in recent years, Nigeria is experiencing accelerating economic growth and is a lower middle-income country (World Bank 2015). There is potential for exploring the impact of introducing a universal pension for the older population in future research.

The implications of economic vulnerability extend to the important area of health. In Nigeria's health system, both rich and poor households pay the same amount for health care, therefore, income becomes an important factor in preventing catastrophic health spending for economically vulnerable households. In an earlier study, I found that richer households are less likely to incur catastrophic health expenditure compared to poorer households, supporting the case for a targeted approach for the most economically disadvantaged households with older persons (see Adisa 2015 for a more thorough discussion).

\section{Conclusion}

The purpose of this paper has been to empirically investigate why some older people are likely to be more economically vulnerable than other groups of older people, using a reduced form household consumption model. I have identified key correlates of economic vulnerability from the empirical analysis using the NGHPS 2010 (http://microdata.worldbank.org/index.php/catalog/1002), as age of household head, household structure, household size, and regional location. This paper has presented policy recommendations that portray an understanding of the economic and political contexts as well as the economic welfare needs of the older people. Identifying the key drivers of economic vulnerability is a good starting point in generating evidence on those older people that are likely to be economically vulnerable and whose needs should be prioritised in Nigeria.

Author's Contribution $\mathrm{OA}$ conceived the study as part of a $\mathrm{PhD}$ thesis at the University of Nottingham. She performed all the statistical analysis, and drafted the manuscript.

\section{Compliance with Ethical Standards}

Conflict of Interest The author declares no conflict of interest.

Informed Consent Informed Consent was not required for this study as it utilises secondary analysis.

Ethical Treatment of Experimental Subjects (Animals and Human) This article does not contain any studies with human participants or animal subjects. 


\section{Appendix}

Table 6 Definitions and variables of interest

\begin{tabular}{|c|c|}
\hline Variable & Definition \\
\hline \multicolumn{2}{|l|}{ Household level variables } \\
\hline Log Consumption per capita & Welfare measure of economic vulnerability \\
\hline \multicolumn{2}{|l|}{ Gender: } \\
\hline Female & dummy variable (Female $=1,0$ otherwise) \\
\hline Male & dummy variable (male $=1,0$ otherwise $)$ \\
\hline Age & Age of household head \\
\hline Agesquared & the square of age \\
\hline \multicolumn{2}{|l|}{ Age categories: } \\
\hline $15-49$ & dummy variable ( $1=$ household head is aged $15-49,0$ otherwise) \\
\hline $50-59$ & dummy variable ( $1=$ household head is aged $50-59,0$ otherwise) \\
\hline $60-69$ & dummy variable ( $1=$ household head is aged $60-69,0$ otherwise) \\
\hline $70-89$ & dummy variable ( $1=$ household head is aged $70-89,0$ otherwise) \\
\hline $90-$ & dummy variable ( $1=$ household head is aged 90 plus, 0 otherwise) \\
\hline \multicolumn{2}{|l|}{ Marital status: Marital } \\
\hline Married & proportion of married heads \\
\hline Widowed & proportion of widowed, divorced or separated heads \\
\hline (a)Never married & proportion of unmarried heads \\
\hline \multicolumn{2}{|l|}{ Sector of employment: OccuSec } \\
\hline Public & dummy variable ( 1 = works in government., 0 otherwise) \\
\hline Private & dummy variable ( $1=$ works in private sector., 0 otherwise) \\
\hline Religious & dummy variable ( $1=$ works in religious org., 0 otherwise) \\
\hline Self employed & dummy variable ( 1 = works in self-employment., 0 otherwise) \\
\hline $\begin{array}{l}\text { Other classifications } \\
\text { (not easily classified) }\end{array}$ & dummy variable ( $1=$ works in other., 0 otherwise $)$ \\
\hline \multicolumn{2}{|l|}{ Education level: } \\
\hline University/Nursing - Highly educated & household heads with advanced education (B.Sc and above) \\
\hline Senior Secondary/A Levels & $\begin{array}{l}\text { household heads with senior secondary education } \\
\text { (B.Sc and above) }\end{array}$ \\
\hline Junior Secondary/Vocational College & household heads with secondary education (B.Sc and above) \\
\hline Primary & household heads with primary education (B.Sc and above) \\
\hline Illiterate/ Semi-illiterate & dummy variable ( $1=$ no education, 0 otherwise) \\
\hline Less educated (E2+ E3+ E4) & dummy variable ( $1=$ has primary education and less, 0 otherwise) \\
\hline Highly educated & dummy variable ( 1 = has advanced education, 0 otherwise) \\
\hline Years of schooling & number of years of schooling \\
\hline \multicolumn{2}{|l|}{ Region: } \\
\hline North central & households reside in North Central Nigeria \\
\hline North east & households reside in North East Nigeria \\
\hline North west & households reside in North West Nigeria \\
\hline South east & households reside in South East Nigeria \\
\hline South south & households reside in South South Nigeria \\
\hline South west & households reside in South West Nigeria \\
\hline
\end{tabular}


Table 6 (continued)

\begin{tabular}{ll}
\hline Variable & Definition \\
\hline $\begin{array}{l}\text { Home ownership status: } \\
\text { Owns a home }\end{array}$ & dummy variable $(1=$ owns home, 0 otherwise $)$ \\
Free housing & dummy variable $(1$ = has authorised free housing, 0 otherwise $)$ \\
Free housing non-authorised & dummy variable (1- has unauthorised free housing, 0 otherwise $)$ \\
Rental housing & dummy variable ( 1 = lives in rented accommodation, 0 otherwise $)$ \\
Household $(\mathrm{HH})$ size & Household Size \\
Household size $(\mathrm{HH})$ squared & square of household size \\
\hline
\end{tabular}

Table 7 OLS and Quantile regression results of correlates of consumption allocation

Dependent Variable $=$ Log of Consumption Per Capita

\begin{tabular}{|c|c|c|c|c|c|}
\hline & OLS & Q0.25 & Q0.50 & Q0.75 & Q0.90 \\
\hline \multicolumn{6}{|c|}{ Age category: Reference: $15-49$} \\
\hline $50-59$ & $\begin{array}{l}-0.049 \\
(0.238)\end{array}$ & $\begin{array}{l}0.031 \\
(0.261)\end{array}$ & $\begin{array}{l}0.048 \\
(0.197)\end{array}$ & $\begin{array}{l}-0.566^{*} \\
(0.234)\end{array}$ & $\begin{array}{l}-0.466 \\
(0.297)\end{array}$ \\
\hline $60-69$ & $\begin{array}{l}-0.241 \\
(0.242)\end{array}$ & $\begin{array}{l}-0.128 \\
(0.267)\end{array}$ & $\begin{array}{l}-0.054 \\
(0.202)\end{array}$ & $\begin{array}{l}-0.634^{* *} \\
(0.239)\end{array}$ & $\begin{array}{l}-0.567+ \\
(0.304)\end{array}$ \\
\hline $70-79$ & $\begin{array}{l}-0.168 \\
(0.257)\end{array}$ & $\begin{array}{l}-0.125 \\
(0.286)\end{array}$ & $\begin{array}{l}-0.065 \\
(0.216)\end{array}$ & $\begin{array}{l}-0.645^{*} \\
(0.256)\end{array}$ & $\begin{array}{l}-0.558+ \\
(0.326)\end{array}$ \\
\hline $80-89$ & $\begin{array}{l}-0.417 \\
(0.302)\end{array}$ & $\begin{array}{l}-0.493 \\
(0.346)\end{array}$ & $\begin{array}{l}-0.310 \\
(0.261)\end{array}$ & $\begin{array}{l}-0.812^{* *} \\
(0.310)\end{array}$ & $\begin{array}{l}-0.341 \\
(0.394)\end{array}$ \\
\hline $90+$ & $\begin{array}{l}-0.983+ \\
(0.520)\end{array}$ & $\begin{array}{l}-1.547 * \\
(0.722)\end{array}$ & $\begin{array}{l}-0.715 \\
(0.545)\end{array}$ & $\begin{array}{l}-1.090+ \\
(0.647)\end{array}$ & $\begin{array}{l}-0.868 \\
(0.823)\end{array}$ \\
\hline HH size & $\begin{array}{l}-0.242 * * * \\
(0.046)\end{array}$ & $\begin{array}{l}-0.215^{* *} \\
(0.080)\end{array}$ & $\begin{array}{l}-0.263 * * * \\
(0.060)\end{array}$ & $\begin{array}{l}-0.227^{* *} \\
(0.072)\end{array}$ & $\begin{array}{l}-0.306 * * * \\
(0.091)\end{array}$ \\
\hline $\mathrm{HH}$ size squared & $\begin{array}{l}0.007 * * * \\
(0.002)\end{array}$ & $\begin{array}{l}0.005 \\
(0.005)\end{array}$ & $\begin{array}{l}0.009 * \\
(0.003)\end{array}$ & $\begin{array}{l}0.006 \\
(0.004)\end{array}$ & $\begin{array}{l}0.011 * \\
(0.005)\end{array}$ \\
\hline \multicolumn{6}{|c|}{ Region (Reference: North central } \\
\hline North east & $\begin{array}{l}-0.464 * * \\
(0.178)\end{array}$ & $\begin{array}{l}-0.387 \\
(0.285)\end{array}$ & $\begin{array}{l}-0.513 * \\
(0.215)\end{array}$ & $\begin{array}{l}-0.446+ \\
(0.256)\end{array}$ & $\begin{array}{l}-0.468 \\
(0.325)\end{array}$ \\
\hline North west & $\begin{array}{l}-0.414 * \\
(0.174)\end{array}$ & $\begin{array}{l}-0.524^{*} \\
(0.249)\end{array}$ & $\begin{array}{l}-0.410^{*} \\
(0.188)\end{array}$ & $\begin{array}{l}-0.432+ \\
(0.223)\end{array}$ & $\begin{array}{l}-0.430 \\
(0.284)\end{array}$ \\
\hline South east & $\begin{array}{l}-0.498 * * \\
(0.176)\end{array}$ & $\begin{array}{l}-0.512 * \\
(0.227)\end{array}$ & $\begin{array}{l}-0.427 * \\
(0.172)\end{array}$ & $\begin{array}{l}-0.420 * \\
(0.204)\end{array}$ & $\begin{array}{l}-0.230 \\
(0.259)\end{array}$ \\
\hline South south & $\begin{array}{l}-0.052 \\
(0.179)\end{array}$ & $\begin{array}{l}-0.294 \\
(0.232)\end{array}$ & $\begin{array}{l}-0.061 \\
(0.175)\end{array}$ & $\begin{array}{l}0.013 \\
(0.208)\end{array}$ & $\begin{array}{l}-0.040 \\
(0.265)\end{array}$ \\
\hline South west & $\begin{array}{l}-0.218 \\
(0.137)\end{array}$ & $\begin{array}{l}-0.254 \\
(0.202)\end{array}$ & $\begin{array}{l}-0.257+ \\
(0.153)\end{array}$ & $\begin{array}{l}-0.196 \\
(0.181)\end{array}$ & $\begin{array}{l}-0.350 \\
(0.231)\end{array}$ \\
\hline One generation $\mathrm{HH}$ & $\begin{array}{l}0.587 * * \\
(0.193)\end{array}$ & $\begin{array}{l}0.669 * \\
(0.297)\end{array}$ & $\begin{array}{l}0.569 * \\
(0.224)\end{array}$ & $\begin{array}{l}0.716^{* *} \\
(0.266)\end{array}$ & $\begin{array}{l}0.599+ \\
(0.339)\end{array}$ \\
\hline Two generation $\mathrm{HH}$ & $\begin{array}{l}0.504 * \\
(0.233)\end{array}$ & $\begin{array}{l}0.591+ \\
(0.348)\end{array}$ & $\begin{array}{l}0.715 * * \\
(0.263)\end{array}$ & $\begin{array}{l}0.366 \\
(0.312)\end{array}$ & $\begin{array}{l}0.130 \\
(0.397)\end{array}$ \\
\hline
\end{tabular}


Table 7 (continued)

\begin{tabular}{llllll} 
Dependent Variable = Log of Consumption Per Capita & & & \\
\hline & OLS & Q0.25 & Q0.50 & Q0.75 & Q0.90 \\
\hline Older head and Adult child & $-0.440+$ & -0.525 & $-0.678^{*}$ & -0.257 & 0.045 \\
& $(0.259)$ & $(0.393)$ & $(0.297)$ & $(0.353)$ & $(0.448)$ \\
Older head and Grandchild & -0.462 & -0.195 & $-0.650+$ & 0.077 & -0.178 \\
& $(0.374)$ & $(0.457)$ & $(0.345)$ & $(0.409)$ & $(0.520)$ \\
Three generational HH & 0.337 & 0.063 & 0.056 & $0.826 *$ & 0.430 \\
& $(0.287)$ & $(0.397)$ & $(0.300)$ & $(0.356)$ & $(0.453)$ \\
Four generational HH & -0.088 & -0.291 & -0.167 & 0.163 & 0.030 \\
NEC multiple HHs & $(0.162)$ & $(0.235)$ & $(0.178)$ & $(0.211)$ & $(0.268)$ \\
& 0.039 & 0.270 & -0.060 & -0.028 & -0.041 \\
Intercept & $(0.192)$ & $(0.496)$ & $(0.375)$ & $(0.445)$ & $(0.566)$ \\
$\mathrm{R}^{2}$ & $12.347 * * *$ & $11.795 * * *$ & $12.200^{* * *}$ & $13.457 * * *$ & $14.074 * * *$
\end{tabular}

Standard errors in parentheses. HH-denotes households. Statistical significance is denoted by: $+p<0.10$ $(10 \%),{ }^{*} p<0.05(5 \%),{ }^{*} p<0.01(1 \%)$, and $* * * p<0.001(0.1 \%)$. Model also includes: housing tenure choice controls, education, occupation, and gender

Source: NGHPS 2010 (http://microdata.worldbank.org/index.php/catalog/1002) (urban older households sample)

Prior to joining the University of Suffolk in March 2017, Olumide worked as the Research Lead examining live at home (LAH) schemes in the UK and the role of third sector partnership working at the Methodist Homes (MHA) in helping older people live independently in their homes. She completed her $\mathrm{PhD}$ in economic sociology in Nottingham in 2016. Her doctoral thesis primarily applied statistics and econometric modelling to investigate and understand the determinants and the health consequences of economic vulnerability amongst ageing households in West Africa - using the NGHPS dataset collected by the World Bank and NBS in 2004 and 2010. She is extending the use of these household datasets to explore other health equity and vulnerability issues.

Olumide has a cross-disciplinary research experience straddling both economics and sociology. Her core specialisms are in applying economic and sociological methods in the fields of domestic violence, social exclusion, health equity, and economic development. She also teaches and contributes to development economics and research methodology courses.

Open Access This article is distributed under the terms of the Creative Commons Attribution 4.0 International License (http://creativecommons.org/licenses/by/4.0/), which permits unrestricted use, distribution, and reproduction in any medium, provided you give appropriate credit to the original author(s) and the source, provide a link to the Creative Commons license, and indicate if changes were made.

Publisher's Note Springer Nature remains neutral with regard to jurisdictional claims in published maps and institutional affiliations. 


\section{References}

Aboderin, I. (2010) Global ageing: Perspectives from sub-Saharan Africa. The SAGE handbook of social gerontology, 405.

Adisa, O. (2015). Investigating determinants of catastrophic health spending among poorly insured elderly households in urban Nigeria. International Journal for Equity in Health, 14(1), 79.

Adisa, O. O. (2016) The determinants and consequences of economic vulnerability among urban elderly Nigerians. $\mathrm{PhD}$ thesis, University of Nottingham.

Alam, M. (2006). Ageing in India: socio-economic and health dimensions (Vol. 66). Academic Foundation.

Alem, Y., \& Söderbom, M. (2012). Household-level consumption in urban Ethiopia: the effects of a large food price shock. World Development, 40, 146-162.

Alessie, R., \& De Ree, J. (2009). Explaining the hump in life cycle consumption profiles. De Economist, 157, 107-120.

Anyanwu, J. C. (2011). Towards reducing poverty in Nigeria: the case of Igboland. Journal of Economics and International Finance, 2, 513-528.

Appleton, S. (1996). Women-headed households and household welfare: An empirical deconstruction for Uganda. World Development, 24, 1811-1827.

Appleton, S. (2000). Education and health at the household level in sub-Saharan Africa. Cambridge: Center for International Development at Harvard University.

Appleton, S., McKay, A., \& Alayande, B. A. (2008). Poverty in Nigeria. Economic options for a prosperous Nigeria (pp. 331-371). Basingstoke: Palgrave Macmillan.

Aribigbola, A. (2008). Housing policy formulation in developing countries: Evidences of programme implementation from Akure, Ondo state Nigeria. Journal of Human Ecology, 23, 125-134.

Barrientos, A. (2004) Cash transfers for older people reduce poverty and inequalitye.

Barrientos, A. (2007) Introducing basic social protection in low-income countries: Lessons from existing programmes. Brooks World Poverty Institute Working Paper.

Barrientos, A., \& Villa, J. M. (2015). Evaluating antipoverty transfer Programmes in Latin America and subSaharan Africa. Better policies? Better politics? In Journal of globalization and development (Vol. 6).

Barrientos, A., Gorman, M., \& Heslop, A. (2003). Old age poverty in developing countries: Contributions and dependence in later life. World Development, 31, 555-570.

Becker, G. S. (1964). Human capital: a theoretical and Empirical Analysis, with Special Reference to Education, by Gary S. Becker, London.

Becker, G. S. (1973). A Theory of Marriage: Part I. Journal of Political Economy, 81, 813-846.

Becker, G. S. (1974). A Theory of Marriage: Part II. Journal of Political Economy, 82, S11-S26.

Calasanti, T. (2010a). Gender and ageing in the context of globalization. The sage handbook of social gerontology, 137.

Calasanti, T. (2010b). Gender relations and applied research on aging. The Gerontologist, 50, 720-734.

Börsch-Supan, A. (1992). Saving and consumption patterns of the older people. Journal of Population Economics, 5, 289-303.

Case, A. (2004) Does money protect health status? Evidence from south African pensions. Perspectives on the economics of aging. University of Chicago Press.

Casey, B. H. (2011). Pensions in Nigeria: The performance of the new system of personal accounts. International Social Security Review, 64, 1-14.

Castañeda, A., Doan, D., Newhouse, D., Nguyen, M. C., Uematsu, H., \& Azevedo, J. P. (2018). A new profile of the global poor. World Development, 101, 250-267.

Clarke, K. A. (2005). The phantom menace: Omitted variable bias in econometric research. Conflict Management and Peace Science, 22, 341-352.

De Vos, S. (2005). Indicating socioeconomic status among older people in developing societies: An example from Brazil. Social Indicators Research, 73, 87-108.

Deaton, A. (1992). Understanding consumption. Oxford University Press.

Deaton, A. (1997) The analysis of household surveys: A microeconometric approach to development policy, World Bank Publications.

Deaton, A. \& Paxson, C. (1995) Measuring poverty among the older people. National Bureau of Economic Research.

Deaton, A., \& Paxson, C. (1998a). Economies of scale, household size, and the demand for food. Journal of Political Economy, 106, 897-930.

Deaton, A. S., \& Paxson, C. H. (1998b). Aging and inequality in income and health. The American Economic Review, 88, 248-253. 
Devereux, S., \& White, P. (2010). Social protection in Africa: Evidence, politics and rights. Poverty \& Public Policy, 2, 53-77.

Doss, C. (2013). Intrahousehold bargaining and resource allocation in developing countries. The World Bank Research Observer, 28, 52-78.

Duflo, E. (2003). Grandmothers and granddaughters: Old-age pensions and Intrahousehold allocation in South Africa. The World Bank Economic Review, 17, 1-25.

Estes, C. L., Lee, P. R., Gerard, L. E. \& Noble, M. (1979) The aging enterprise, Jossey-Bass San Francisco.

Fox, M. L. (2015). Are African Households Heterogeneous Agents?: Stylized Facts on Patterns of Consumption, Employment, Income and Earnings for Macroeconomic Modelers, International Monetary Fund.

Giddens, A. (2009). Sociology (6th edition). Cambridge: Polity Press.

Grootaert, C. (1997). The determinants of poverty in Cote d'Ivoire in the 1980s. Journal of African Economies, $6,169-196$.

Grundy, E. (2006). Ageing and vulnerable elderly people: European perspectives. Ageing and Society, 26, $105-134$.

Harris, D. (2007) The sociology of aging. Lanham, Boulder, New York, Toronto, Plymouth, UK. Rowman \& Littlefield Publishers, Inc.

Himaz, R. \& Aturupane, H. (2011). Education and household welfare in Sri Lanka from 1985 to 2006, Department of Economics, University of Oxford.

Johnson, M. L., Bengtson, V. L., Coleman, P. G., \& Kirkwood, T. B. (2005). The Cambridge handbook of age and ageing. Cambridge: Cambridge University Press.

Kakwani, N. \& Subbarao, K. (2005) Ageing and poverty in Africa and the role of social pensions, United Nations Development Programme, International Poverty Centre.

Lam, D., Murray, L., \& Vimal, R. (2006). Labor force withdrawal of the elderly in South Africa. In Advancing the research agenda on aging in Africa (pp. 214-249). Washington DC: National Academies Press.

Lloyd-Sherlock, P. (2006). Identifying vulnerable older people: Insights from Thailand. Ageing and Society, 26, 81-103.

Lloyd-Sherlock, P., Corso, B., \& Minicuci, N. (2015). Widowhood, socio-economic status, health and wellbeing in low and middle-income countries. The Journal of Development Studies, 51(10), 1374-1388.

Lloyd-Sherlock, P., Mayston, R., Acosta, A., Gallardo, S., Guerra, M., Sosa, A. L., et al. (2018). Allocating family responsibilities for dependent older people in Mexico and Peru. The Journal of Development Studies, 54(4), 682-701.

Maharaj, P. (2012) Aging and health in Africa, Springer Science \& Business Media.

Maitra, P., \& Ray, R. (2003). The effect of transfers on household expenditure patterns and poverty in South Africa. Journal of Development Economics, 71, 23-49.

Mberu, B. U. (2007). Household structure and living conditions in Nigeria. Journal of Marriage and Family, 69, 513-527.

Modigliani, F. \& Brumberg, R. 1954. Utility analysis and the consumption function: An interpretation of cross-section data. FRANCO MODIGLIANI, 1.

Mukherjee, S., \& Benson, T. (2003). The determinants of poverty in Malawi, 1998. World Development, 31, 339-358.

Ndubueze, O. J. (2009) Urban housing affordability and housing policy dilemmas in Nigeria. University of Birmingham.

Niño-Zarazúa, M., Barrientos, A., Hickey, S., \& Hulme, D. (2012). Social protection in sub-Saharan Africa: Getting the politics right. World Development, 40, 163-176.

NPC 2003. The Older people: Nigerian Population Census 1991 Analysis. Abuja: National Population Commission.

O’brien, R. M. (2007). A caution regarding rules of thumb for variance inflation factors. Quality \& Quantity, $41,673-690$.

O'Donnell, O., van Doorslaer, E., Rannan-Eliya, A. \& Somanathan, C. (2005) Erasmus University, Rotterdam, Netherlands, and Institute of Policy studies.

Okojie, C. E. (2002) Gender and education as determinants of household poverty in Nigeria, WIDER discussion papers//world Institute for Development Economics (UNU-WIDER).

Oppong, C. (2006). Familial roles and social transformations older men and women in sub-Saharan Africa. Research on Aging, 28, 654-668.

Phillipson, C. \& Dannefer, D. (2010) The SAGE handbook of social gerontology, Sage.

Quisumbing, A. R., Haddad, L., \& Peña, C. (2001). Are women overrepresented among the poor? An analysis of poverty in 10 developing countries. Journal of Development Economics, 66, 225-269.

UN (2013a). World population 2012. New York: Department of Economic and Social Affairs. United Nations. 
UN (2013b). World Population Ageing. In: Nations, U. (ed.). New York.

UNFPA \& HAI (2012) Ageing in the Twenty-First Century: A Celebration and a Challenge.

Van de Walle, D. (2013). Lasting welfare effects of widowhood in Mali. World Development, 51, 1-19.

Velkoff, V. A. \& Kowal, P. R. (2007) Population aging in Sub-Saharan Africa: demographic dimensions 2006, US Dept. of Commerce, Economics and Statistics Administration, US Census Bureau.

Walker, A. \& Foster, L. (2014) The Political Economy of Ageing and Later Life, Cheltenham, UK, 'Edward Elgar Publishing, Inc.'.

Woolard, I., \& Klasen, S. (2005). Determinants of income mobility and household poverty dynamics in South Africa. Journal of Development Studies, 41, 865-897.

World Bank (2015). World Development Indicators. Washington DC.

Zimmer, Z., \& Das, S. (2013). The poorest of the poor: composition and wealth of older person households in Sub-Saharan Africa. Research on Aging. https://doi.org/10.1177/0164027513484589.

Olumide Adisa Prior to joining the University of Suffolk in March 2017, Olumide worked as the Research Lead examining live at home (LAH) schemes in the UK and the role of third sector partnership working at the Methodist Homes (MHA) in helping older people live independently in their homes. She completed her PhD in economic sociology in Nottingham in 2016. Her doctoral thesis primarily applied statistics and econometric modelling to investigate and understand the determinants and the health consequences of economic vulnerability amongst ageing households in West Africa - using the NGHPS dataset collected by the World Bank and NBS in 2004 and 2010. She is extending the use of these household datasets to explore other health equity and vulnerability issues.

Olumide has a cross-disciplinary research experience straddling both economics and sociology. Her core specialisms are in applying economic and sociological methods in the fields of domestic violence, social exclusion, health equity, and economic development. She also teaches and contributes to research and evaluation methodology courses. 